Behavior and Social Issues, 23, 20-34 (2014). C Patricia Frazer \& Julian Leslie. Readers of this article may copy it without the copyright owner's permission, if the author and publisher are acknowledged in the copy and the copy is used for educational, not-for-profit purposes. doi: $10.5210 /$ bsi.v.23i0.4324

\title{
FEEDBACK AND GOAL-SETTING INTERVENTIONS TO REDUCE ELECTRICITY USE IN THE REAL WORLD
}

\author{
Patricia Frazer \\ Dublin Business School \\ Julian Leslie \\ University of Ulster, Coleraine
}

\begin{abstract}
A field experiment explored the effect of feedback and goal-setting interventions on residential electricity use in households in Northern Ireland. Alternating orders of presentation of feedback and no feedback conditions were used to explore the longer-term effect of feedback on conservation performance. Group 1 received 5 months of feedback followed by 5 months of no feedback, Group 2 underwent 5 months of no feedback followed by 5 months of feedback, and Group 3 experienced alternating 2-month periods of feedback and no feedback over 10 months, using a reversal design. Group 1 saved a mean $9.54 \%$ of electricity during the feedback condition, but Group 2 increased their use by a mean $14.24 \%$. Group 3 showed a pattern of cumulative reductions over successive feedback periods, with a mean reduction in electricity use of 33\%. Participants in Group 3 did not show a return to baseline levels of electricity use during the no feedback condition. The importance of exploring different reactions to feedback is discussed.
\end{abstract}

KEYWORDS: environmental action, feedback, goal-setting, energy use

There is an urgent need for applied behavior analytic research on energy conservation to be conducted in the field for the following reasons. Firstly, there is no obvious link between the attitudinal research that is extensively conducted and the production of technologies for real behavior change. Secondly, behavior analytic research is underrepresented in the emerging field of Ecopsychology. Lastly, there is sufficient evidence of the effectiveness of behavior change techniques in controlled circumstances, but solutions proposed by behaviorists interested in social change are irrelevant if they cannot be tried and tested in the real world.

\section{Problems with Attitudinal Research}

Although campaigns to change attitudes are often the knee-jerk response of policy makers to identified needs for behavior change in the community, there are serious limitations to this approach. One well-documented limitation is that self-reported attitudes or intentions do not strongly predict actual behavior (Bamberg, 2003; Kaiser, Wolfing \& Fuhrer, 1999). So, although the majority of research into pro-environmental behavior (PEB) has been based on studies of self-reported attitudes (Lehman \& Geller, 2004), this approach is unlikely to yield any solutions to the immediate problem of decreasing energy waste. Self-reported environmental behavior may 
be a poor reflection of the real behaviors that researchers are seeking to change (Chao \& Lam, 2011).

Some research has combined measurement of attitude towards the environment with directly observable behaviors. For example, Brandon and Lewis (1999) found that self-reported beliefs about the environment predicted responses to energy use feedback in households in England, leading to a reduction in energy use for previously high-level users who held positive beliefs. Guagnano, Stern and Dietz (1995) also found that strong environmental concern combined with a self-reported feeling of personal responsibility predicted recycling behavior in areas where there were high external barriers to recycling (no curbside recycling), but not in areas where curbside collections made recycling easy for most people.

Such examples indicate that attitudinal variables may have a role to play in understanding environmental behaviors, and yet, while attitudes of environmental concern have been increasing for some time (Gardner \& Stern, 2002), energy consumption has not been decreasing. Such proenvironmental attitudes are often reported to be highest in the nations which are most wealthy and therefore consuming the most energy per capita (Franzen, 2003). This suggests that relying heavily on attitude change as a means to alter actual behavior is unlikely to result in success.

\section{The Contribution of Behavior Analysis to Ecopsychology}

The field of Ecopsychology has developed rapidly to the point where it now has its own journals (e.g. Conservation Psychology, Ecopsychology) as well as considerable presence in the journals of general environmental psychology. However, in their 2004 review paper on behavior analytic approaches to environmental issues, Lehman and Geller mourned the relatively small contribution of behavioral psychologists to this emerging field in comparison to other disciplines in psychology. They described an "almost linear" decline in the number of papers on behavioral interventions during the 1980s and 1990s, after an initial flurry of interest during the oil crisis of the 1970s (Lehman \& Geller, 2004, p. 13).

Early work by behavior analysts in this field was promising, particularly in the area of energy consumption. For example Palmer, Lloyd and Lloyd (1977) used behavioral intervention techniques such as various forms of prompting and feedback to achieve a mean reduction in daily electricity use of $35 \%$ on a sample of four families, also illustrating some reversal of intervention effects during periods when interventions were removed. Becker (1978) used feedback interventions to achieve reductions of 5-15\% in energy use. Feedback was combined with setting low (5\% reduction) and high $(20 \%$ reduction) conservation targets. The results revealed that the greatest savings were made in the group where feedback was combined with a high conservation target.

However, in the Becker study, as in that by Palmer et al. (1977), feedback was provided by researchers attaching notices to participants' front doors on a daily basis, making it time and resource intensive to administer on a large scale. Hayes and Cone (1981) illustrated the effectiveness of more economical forms of feedback using monthly letters to participants, comparing the previous month's use to the same month during a preceding baseline period. The feedback group reduced electricity use by $4.7 \%$ over a four month intervention period, in comparison to a $2.3 \%$ increase in use in the control group. This effect was reversed when the intervention was removed. Winett et al. (1982) also achieved reductions in electricity use of 1-22\% of baseline use, using different combinations of feedback, information on conservation, and television programs, by either modeling conservation behaviors or showing discussions of the 
seriousness of the energy crisis, across both winter and summer in exclusively electricity powered townhouses. The lowest savings (1\%) were achieved by providing only information and a discussion television program. Combining information with modeling led to savings of $11 \%$, and combining feedback with modeling led to savings of $14 \%$ in a wintertime intervention and $22 \%$ in a summertime intervention.

Although this early work seemed extremely promising, Lehman and Geller (2004) note the declining relative focus on behavioral interventions in the more recent literature. Their literature search revealed only 32 behavioral papers published between 1990 and 2004, but they noted that articles focusing on environmental attitudes or survey-type research outnumbered behavioral ones 7:1 in the journal, Environment and Behavior.

\section{The Need for Field Work}

In a summary of journal special issues focusing on environmental problems, Pelletier, Lavergne and Sharp (2008) stressed the need for "assessment of real behaviors, not only intentions to act, and multiple assessments of behaviors over time will be especially important to determine the effectiveness of strategies designed to enhance PEBs" (p. 307). They concluded that a major challenge for environmental psychology is in putting a "wealth" of behavioral research into practice by designing and applying interventions, echoing the conclusions of Lehman \& Geller (2004). While it is true that the lack of internal validity and rigorous control of confounding variables in field research seriously limits inferences about cause and effect (Cook \& Campbell, 1979), it is also true that all the theoretical knowledge in the world is of no use to society if we do not explore the ecological validity of our theories by testing them in the real world. With this pressing need to increase the ecological validity and social relevance of Ecopsychology in mind, we developed a behavioral intervention in a series of field experiments to reduce domestic electricity use and applied it to households in Northern Ireland. Our interventions were designed to minimize interaction with and monitoring by the researcher. This was done to emulate conditions under which such techniques might be someday used to change behavior on a wide scale.

\section{The Interventions}

Although there is a relative lack of studies of PEB using behavioral intervention methods in comparison with the study of pro-environmental attitudes and self-reported behavior, two reviews of studies in this area have been published (Lehman \& Geller, 2004; Abrahamse, Steg, Vlek \& Rothengatter, 2005). Both concluded that several interventions showed promising effects, such as providing performance feedback for conservation tasks (Becker, 1978) and setting specific goals (Pallak \& Cummings, 1976), and both reviews also noted that combining interventions to increase PEB may be more effective than using them in isolation. The maintenance of desirable behaviors once established has been under-addressed by previous work (Abrahmse et al. 2005; Darby, 2006a; Lehman \& Geller, 2004). For example, of 21 studies involving feedback interventions on energy use, identified for inclusion in a review by Abrahmse et al. (2005), only six included attempts to follow up with participants and look at whether their energy use returned to previously high levels after the intervention had ceased. Winett, Neale and Grier (1979) reported reduced electricity use 10 weeks after follow up and Staats, Harland and Wilke (2004) reported reduced gas, water and electricity use after two years using information 
and individual and comparative feedback, but the remaining four studies using follow ups showed that initial conservation behaviors were not maintained (Van Houweligen \& Van Raaij, 1989; Sexton, Brown Johnson \& Konakayama, 1987; Hayes \& cone, 1981; Katzev, Cooper \& Fisher, 1980-81).

Lehman and Geller (2004) noted that efforts would be most efficient if focused in accordance with the popular environmental slogan, "reduce, re-use, recycle", and that concentrating efforts at the top of this cycle has the potential to save the most resources, i.e., we should focus on reducing consumption first. Many behavioral interventions are costly, time consuming, and unnatural (Darby, 2006a), in the sense that they do not fit into a participant's expectations of life as normal, and will come to an end once the period of data collection is over. The interventions for our field project were designed to overcome the weaknesses outlined above in the following ways: To improve effectiveness the intervention used combined techniques (by using feedback and goal-setting together); the intervention was made as unobtrusive and 'natural' as possible so that positive behavior change might easily continue after the research was over; behavior was observed over as long a period as possible so that behavioral maintenance might be explored; and the intervention focused on the 'upstream' behavior of reducing primary energy use, rather than recycling.

A secondary aim was to further explore how and when feedback can be most useful in reducing electricity consumption. Darby (2006b) proposed that feedback results in gains in "tacit knowledge" (p. 2930). If this is the case, then the effects of receiving better feedback should persist, even after the feedback is removed. As noted above, previous research is equivocal on whether behavioral changes can be maintained after removal of a feedback intervention (Abrahamse et al. 2005). We therefore used three different modes of application for our feedback intervention, including various elements of a reversal design, so that more could be learned about behavioral maintenance after a feedback intervention is removed. One group were given 5 months of feedback, and then followed up for a further 5 months after the feedback was removed (no feedback condition). A second group were monitored for 5 months prior to administration of feedback (no feedback), followed by 5 months of feedback. The third group experienced alternating periods where feedback was given, then removed, in order to further explore the conditions under which feedback-related reductions in energy use might be maintained, or disappear.

Our hypotheses were that: 1) intervention-related savings could persist over a five month period; and 2) that a removal of the intervention would result in a return to baseline electricity use during the no feedback condition for Group 1. Such a return to baseline would not be expected if feedback resulted in permanent gains in tacit knowledge about energy use, as Darby (2006b) predicted. The feedback intervention was applied through provision of wireless energy monitors to participating households. These monitors are available for private purchase in the domestic market. No comparison was made between different intervention types, and instead the focus was on behavioral responses to performance feedback over a relatively long time period. Feedback and goal-setting were applied as a combined intervention for all participants in this study, and no attempt was made to separate the effects of feedback from those of goal-setting. The factors justifying this decision were: the extremely controlled conditions necessary to rule out potential confounds in research are usually very difficult to provide in field research; previous research conducted under more controlled conditions has already established that combining interventions leads to improved savings (Lehman \& Geller, 2004; Abrahamse et al. 
2005; Neubert, 1998), and, as previously stated, we intended to maximize the potential of realworld results for the participants involved.

\section{Method}

\section{Participants}

Each participant represented a household of electricity users, and all electricity use figures and interventions apply to the household as a whole. The term 'participant' refers to the individual who was in contact with the researcher, who gave consent to take part and who supplied any electricity meter readings. An opportunity sample of university staff were recruited through the mailing list of the University of Ulster. Of an original 40 participants, 23 responded, and only 18 completed participation by giving all necessary electricity meter reads. In Group 1 (feedback first) there were 6 participants; In Group 2 (no feedback condition first): there were initially 11 participants, and 8 completed participation; in Group 3 (alternating feedback/no feedback) of an initial 6 randomly assigned to this group, 4 went through with participation with one participant failing to give their last meter read, therefore providing data for only four of the five experimental periods. See Table 1 for household composition information.

Due to the small numbers involved combined with attrition and random assignment to group, groups were uneven and unfortunately small in the case of Group 3. No formal analysis of attrition rates was possible due to limited sample sizes. Participants were a variety of staff and postgraduate students from four campuses throughout Northern Ireland.

\section{Materials and Procedure}

The new intervention applied to households hoping to reduce electricity use combined goalsetting and feedback for all participants in an attempt to maximize savings and potential for behavioral maintenance. The goal-setting comprised of having participants sign two copies of a declaration of their intention to reduce their electricity use by $20 \%$. One copy was given to the researcher, making the declaration public by sharing it, and the other copy was retained by the participant as a reminder of their goal.

The feedback aspect of the intervention was administered via provision of free wireless home energy monitors to each participant. The energy monitors used by participants were model CM119 OWL ${ }^{\circledR}$ wireless electricity monitors. The energy monitor works by attaching a sensor clip onto the output cable in one's home electricity meter box. The sensor clip and attached transmitter communicate information about how much electricity is being used to a handheld LCD display box with a $30 \mathrm{~m}$ range, usually kept in a communal living area of the home. The handheld display device shows current total electricity use to householders as well as cumulative use, providing them with constant conservation performance feedback. It performs many functions, such as showing current electricity use in terms of monetary cost, kilowatt hours $(\mathrm{kWh})$, or amount of greenhouse gas being released. It can also display historical electricity use, time, date and temperature. The monitor came with full and easy-to-follow set up instructions. It also came with batteries for the transmitter and hand-held display, ensuring any extra electricity used by a mains-powered monitor did not obscure electricity savings.

Interaction with feedback monitors was not controlled or itself monitored. Participants were left free to interact with their monitor as they saw fit, so the intervention could be experienced as 
FEEDBACK IN THE REAL WORLD

Table 1. Composition of Participating Households

\begin{tabular}{ccccc}
\hline Household & Adults & Adolescents (13-18 years) & Children (0-13 years) & Total \\
\hline A & & Group 1 & & \\
B & 2 & 1 & 3 & 6 \\
C & 2 & 2 & 1 & 5 \\
D & 2 & 0 & 1 & 3 \\
E & 2 & 0 & 0 & 2 \\
F & 2 & 0 & 0 & 2 \\
\hline & 4 & 0 & 0 & 4 \\
\hline G & 2 & Group 2 & & \\
H & 2 & 0 & 0 & 2 \\
I & 1 & 0 & 2 & 4 \\
J & 3 & 0 & 0 & 1 \\
K & 3 & 3 & 0 & 6 \\
L & 1 & 0 & 0 & 3 \\
M & 2 & 0 & 0 & 1 \\
N & 2 & 0 & 3 & 5 \\
\hline & & 0 & 2 & 4 \\
\hline O & 2 & Group 3 & & \\
P & 3 & 2 & 0 & 5 \\
Q & Not given & 1 & 0 & \\
R & 2 & 0 & & \\
\hline
\end{tabular}

a change in the environment which could be continued indefinitely after the research concluded, and would not be dependent on intensive upkeep by a researcher.

There were three experimental groups, but instead of each group experiencing a different intervention, each group experienced the single 'combined' intervention (referred to as 'feedback' condition) in a different order of presentation. Group 1 experienced 5 months of feedback, followed by 5 months of no feedback. Group 2 experienced 5 months of no feedback, followed by 5 months of feedback. Group 3 experienced a B-A-B-A-B reversal design, where they had two months of feedback (intervention 1), followed by two months of no feedback, then a second two months of feedback (intervention 2), a second two months of no feedback (baseline 2), and a last 2 months of feedback (intervention 3).

Interested potential participants were emailed details on the aims and procedures involved in taking part in the study, and informed that if they decided to take part they would be randomly 
assigned (die roll) to one of the three groups determining order of presentation of the feedback/ no feedback conditions. Once group assignment had taken place, each participant was visited at their place of work and given an opportunity to ask questions about the research. Participants from groups 1 and 3 were given their wireless energy monitors at this time. All participants gave written electricity meter readings by post when their participation began, and henceforth at the end of each feedback or no feedback period.

For participants in Group 1, at the end of the first 5 month feedback period, they were sent a letter asking for an electricity meter reading and a pre-addressed padded envelope for the return of their wireless electricity monitor during their no feedback period. Participants in Group 2 were asked to submit an electricity meter reading when they were first recruited on to the study, either by telephone or email, depending on their preferred mode of contact. This reading was used to calculate their levels of electricity use during the following 5 months of the no feedback condition, during which time there was no contact from the researcher. Participants were then sent their wireless electricity monitors, accompanied by a pre-addressed envelope for the return of an electricity meter reading by post, with some participants choosing to give their electricity meter readings by email. Participants in Group 3 received and returned their wireless monitors by post at the beginning and end of each feedback/ no feedback period also. At the end of participation, participants were asked for one last electricity meter reading and told they could now keep their wireless monitors.

Participating households were recruited on an ongoing basis, with each household beginning their first feedback or no feedback period within a week or two of contacting the researcher. This meant that feedback and no feedback periods were occurring over different seasons, and so were not directly confounded by co-occurring changes in temperature or season.

\section{Results}

The dependent variable was electricity used in kWh. Since Groups 1 and 2 experienced only one feedback and one no feedback period each, they were compared on the amount of electricity they used during their feedback condition, and the amount of electricity used during their no feedback condition. These variables were also adjusted for differences in the duration of the conditions between individuals. The $\mathrm{kWh}$ electricity used during the feedback condition was divided by its duration in days, giving a mean day's electricity use during feedback, and the same was done for $\mathrm{kWh}$ no feedback scores. These mean day feedback and mean day no feedback variables could then be multiplied by 150 days ( 5 months) to give $k W h$ feedback and $k W h$ no feedback use scores that were more comparable to each other. For Group 3, the variables used were $k W h$ intervention 1 (feedback), baseline 1 (no feedback), intervention 2 (second feedback period), $k W h$ baseline 2 (second no feedback period) and $k W h$ intervention 3 (third feedback period). These were also corrected for differences in duration of intervention and baseline periods between participants by dividing amount of electricity used by the duration in days, and then multiplying this figure by 60 (60 days $=2$ months). When seeking to compare individuals in Groups 1 and 2 with those from Group 3 who got shorter intervention periods, the variables mean day feedback and mean day no feedback were used. Table 2 illustrates feedback and no feedback condition electricity use figures for each household in all three groups. 
FEEDBACK IN THE REAL WORLD

Table 2. Electricity Used by Households during Each Period

\begin{tabular}{|c|c|c|c|c|c|c|}
\hline Participant & \multicolumn{5}{|c|}{ Mean kWh Electricity Use } & $\begin{array}{l}\text { Proportional } \\
\text { Change }\end{array}$ \\
\hline \multicolumn{7}{|l|}{ Group 1} \\
\hline & \multicolumn{2}{|l|}{ Feedback } & \multicolumn{3}{|l|}{ No Feedback } & \\
\hline A & \multicolumn{2}{|l|}{3048 (Jun) } & \multicolumn{3}{|l|}{3505 (Nov) } & 0.87 \\
\hline B & \multicolumn{2}{|c|}{1523 (May) } & \multicolumn{3}{|l|}{2287 (Oct) } & 0.67 \\
\hline $\mathrm{C}$ & \multicolumn{2}{|l|}{1206 (Jul) } & \multicolumn{3}{|l|}{1428 (Jan) } & 0.84 \\
\hline $\mathrm{D}$ & \multicolumn{2}{|l|}{3159 (Jul) } & \multicolumn{3}{|l|}{2807 (Jan) } & 1.13 \\
\hline $\mathrm{E}$ & \multicolumn{2}{|l|}{1806 (Jun) } & \multicolumn{3}{|l|}{ 1671(Dec) } & 0.91 \\
\hline $\mathrm{F}$ & \multicolumn{2}{|l|}{ 2760(May) } & \multicolumn{3}{|l|}{ 1770(Jan) } & 1.02 \\
\hline \multicolumn{7}{|l|}{ Group 2} \\
\hline & \multicolumn{2}{|c|}{ No Feedback } & \multicolumn{3}{|l|}{ Feedback } & \\
\hline G & \multicolumn{2}{|c|}{1829 (May) } & \multicolumn{3}{|l|}{2760 (Nov) } & 1.52 \\
\hline $\mathrm{H}$ & \multicolumn{2}{|c|}{2220 (May) } & \multicolumn{3}{|l|}{2835 (Nov) } & 1.28 \\
\hline I & \multicolumn{2}{|c|}{1085 (May) } & \multicolumn{3}{|l|}{1329 (Nov) } & 1.23 \\
\hline $\mathrm{J}$ & \multicolumn{2}{|c|}{2631 (May) } & \multicolumn{3}{|l|}{3603 (Nov) } & 1.37 \\
\hline K & \multicolumn{2}{|l|}{1965 (Jul) } & \multicolumn{3}{|l|}{2025 (Jan) } & 1.03 \\
\hline $\mathrm{L}$ & \multicolumn{2}{|l|}{975 (Jun) } & \multicolumn{3}{|l|}{1124 (Dec) } & 1.15 \\
\hline M & \multicolumn{2}{|l|}{813 (Jun) } & \multicolumn{3}{|l|}{$830(\mathrm{Jan})$} & 1.02 \\
\hline $\mathrm{N}$ & 4076 (Jun) & & 2222 (Jan) & & & 0.55 \\
\hline Group 3 & & & & & & \\
\hline & $\begin{array}{c}\text { Intervention } \\
1\end{array}$ & $\begin{array}{c}\text { Baseline } \\
1\end{array}$ & $\begin{array}{c}\text { Intervention } \\
2\end{array}$ & $\begin{array}{c}\text { Baseline } \\
2\end{array}$ & $\begin{array}{c}\text { Intervention } \\
3\end{array}$ & \\
\hline $\mathrm{O}$ & 1836 (May) & $1828(\mathrm{Jul})$ & 1036 (Oct) & $985(\mathrm{Dec})$ & 778 (Mar) & 0.42 \\
\hline $\mathrm{P}$ & 2730 (May) & 2825(Aug) & 1172 (Nov) & $1859(\mathrm{Feb})$ & 708 (Apr) & 0.23 \\
\hline Q & 1273 (Aug) & $1303(\mathrm{Oct})$ & $535(\mathrm{Dec})$ & $521(\mathrm{Feb})$ & 365 (Apr) & 0.29 \\
\hline $\mathrm{R}$ & 2563 (Jul) & 4516 (Sep) & 1315 (Jan) & 900 (Apr) & $\begin{array}{l}\text { Not } \\
\text { submitted }\end{array}$ & 0.35 \\
\hline
\end{tabular}

Note: The months when each feedback or no feedback period began are shown in parentheses. Proportional change scores were calculated for Group 3 by dividing electricity used in the last period of the experiment by the electricity used in the first

Initial results were unexpected. A related t-test was used to compare $\mathrm{kWh}$ mean day intervention with mean day baseline electricity use, and no significant difference was found (it should be noted that the power of this test (1- $\beta$ ) was 0.89$)$, meaning the first hypothesis was rejected, but a more detailed examination of how participants responded differently by order-ofpresentation groups helped to explain this result. The small number of households participating 
within each group meant inferential statistics could not be used to make meaningful comparisons. Further analysis of these results was based on observation of individual and comparative household usage patterns. As can be seen from Table 2, participants in Group 1 did tend to use less electricity in their feedback than in their no feedback condition, with the exception of participants $\mathrm{D}$ and $\mathrm{F}$, who used more (in the case of household $\mathrm{F}$, this difference was very small). Despite these two participants using more, the mean change score for Group 1 was $201.33 \mathrm{kWh}$, and the mean proportional change score was 0.91 . These scores represent substantial savings for the participants of Group 1 during the feedback condition, and higher levels of use during the following no feedback condition. Even including participants D and $\mathrm{F}$ who used more electricity during the feedback condition, the mean saving was the equivalent of $\$ 47.26$ per household over a 5-month period. The mean saving amongst the four households who did use less electricity during their feedback condition was $\$ 93.72$ per household over a 5-month period. However, the participants in Group 2 did not seem to make similar significant savings. In fact, as a group they appeared to use more electricity during the feedback than during the no feedback condition which preceded it, almost mirroring the pattern of use observed for Group 1 (see Figure 1).

All but one of the eight participants in Group 2 used more electricity during their feedback condition than during their preceding no feedback condition. The mean change score for this group was -142.86 , with a mean proportional change score of 1.14 . These participants spent a mean extra $\$ 33.54$ each on electricity during the 5 months of their feedback condition. Participant $\mathrm{N}$ was the only member of Group 2 to succeed in saving electricity, using $1854 \mathrm{kWh}$ less electricity during the feedback than during the no feedback condition, meaning a massive saving of $\$ 435.32$ in 5 months. It may be of note that this participant had the highest baseline use of Group 2, with a mean $27.17 \mathrm{kWh}$ of electricity used per day of the baseline, compared to the next highest mean day baseline use of $17.54 \mathrm{kWh}$ for participant J. Discounting participant N, the remaining seven participants of Group 2 used a mean $428.14 \mathrm{kWh}$ more of electricity during their feedback condition. This is equivalent to spending a mean extra $\$ 100.53$ on electricity each during the 5 month feedback condition, almost negating the approximately $\$ 94$ less electricity used by Group 1 during their feedback condition. The mean baseline electricity use for Group 1 was $2246.45 \mathrm{kWh}$, and for Group 2 (minus participant N) was $1644.09 \mathrm{kWh}$. Another t-test was therefore carried out to explore the possibility that differing levels of baseline use (i.e. use during the no feedback condition) could explain the different responses to feedback in Groups 1 and 2, but the difference between baseline levels was not significant $(\mathrm{t}(12)=1.465, \mathrm{p}=.873,1-\beta=$ $.05)$, however a Pearson's correlation found a significant relationship between electricity use in the no feedback condition and proportional change scores in electricity use $(\mathrm{r}(17)=-.48, \mathrm{p}=$ $.044)$.

For Group 3, who experienced alternating feedback and no feedback conditions, again inferential statistics were inappropriate for a sample of 4 households, but interesting pathways to reduced electricity use by the end of the last feedback period can be observed for each member of the group (see Figure 2). Participants seemed to succeed in saving electricity overall, with a mean proportional change score of 0.86 , and a mean change score of $569.23 \mathrm{kWh}$ for the group, equal to $\$ 133.66$ of electricity saved each over the four months of feedback (intervention 1 and 2 ), versus the four months of no feedback (baseline 1 and 2). 


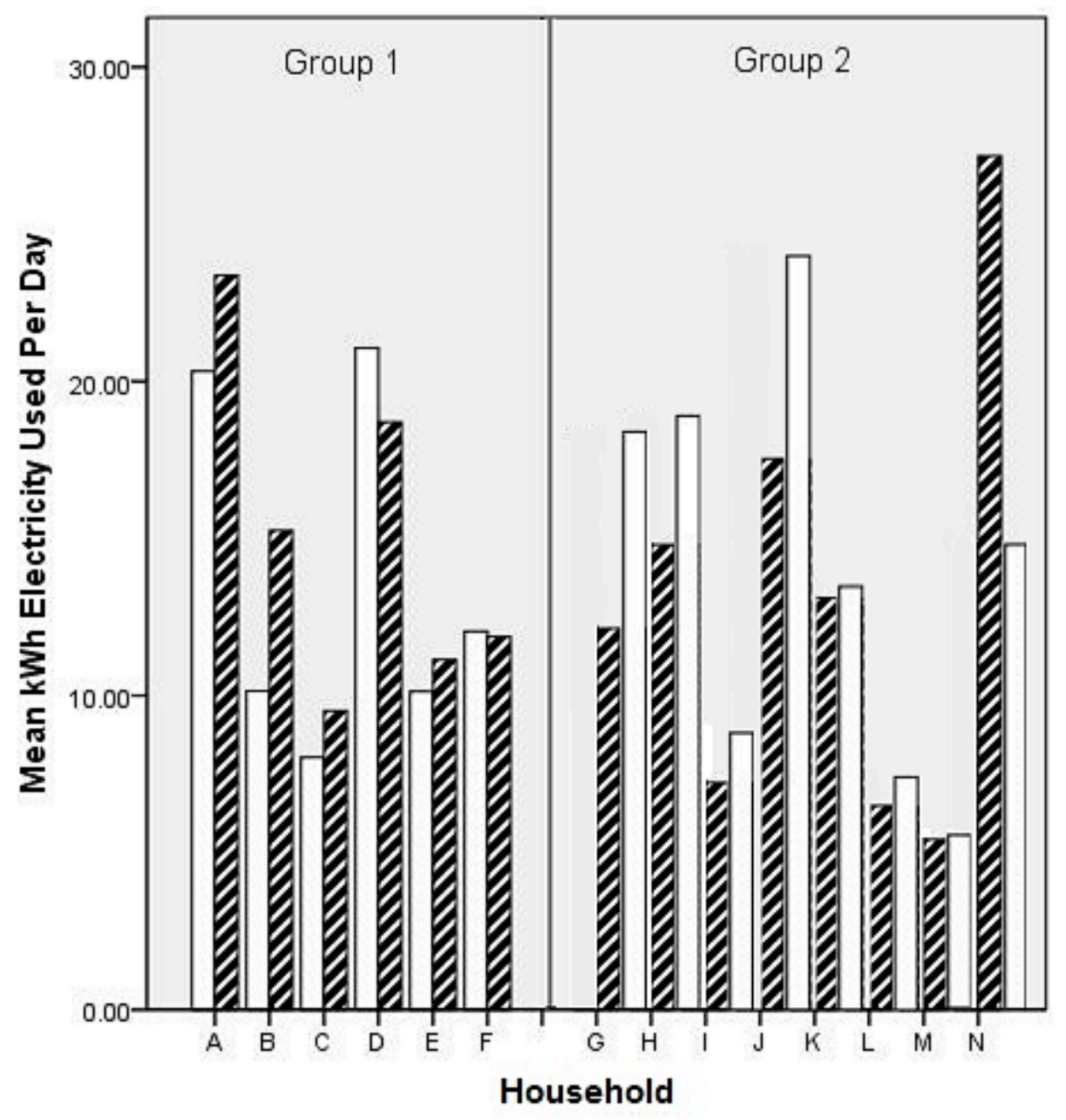

Figure 1. Amounts of daily electricity use by participants in Group 1 (left panel) and Group 2 (right panel). Shading indicates amount of electricity used during baseline (hatched) and intervention (un-shaded).

\section{Discussion}

Lehman and Geller (2004) noted in their review of the contribution of behavioral analysis towards addressing environmental problems that

There is little evidence the effective behavioral interventions that are documented in research journals have escaped their pages to make significant contributions toward solving real-world environmental problems. In other words, the external validity of this research is weak or nonexistent (p. 14).

The findings described here represent an example of behavior analytic approaches escaping the page, and the lab, to reduce energy consumption in the real world. An important aim of this study was to illustrate the effectiveness of feedback through a demonstration of a return to base- 


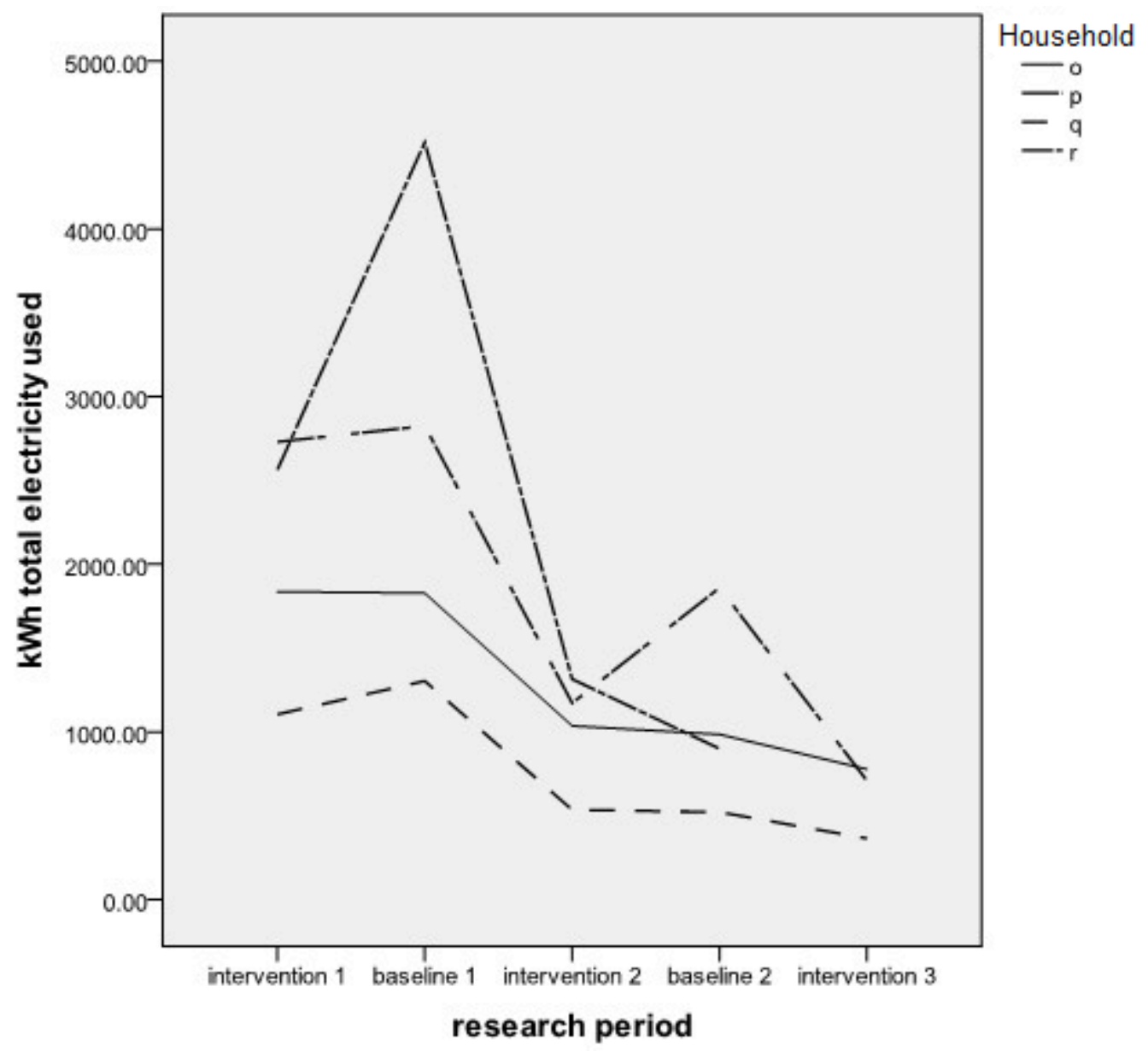

Figure 2. Total amount of electricity used during each two month research period by each participant in Group 3.

line levels of behavior once the feedback intervention was removed in Group 3. Results were unexpected, but nevertheless interesting.

Group 1 successfully reduced their energy use during the feedback condition, and showed a higher level of use during the following no feedback period, which seems incompatible with Darby's (2006b) tacit knowledge hypothesis, and fails to demonstrate behavioral maintenance after the feedback intervention concluded. Group 1 had a mean no feedback condition level of use of $2246.5 \mathrm{kWh}$, whereas Group 2, who used more electricity during feedback than no feedback condition (minus participant N, who did save) had a lower mean no feedback condition use of $1644.1 \mathrm{kWh}$. However it should be noted that the difference between the no feedback use levels of Groups 1 and 2 in the current study was not statistically significant. This lack of significance is likely a reflection of the low statistical power of this comparison, and it should be noted that the correlation between proportional change scores and levels of baseline electricity use was statistically significant. If we take levels of use during the no feedback condition as indicative of baseline or non-intervention levels of use for both groups, then it seems that 
participants with higher baseline levels of use had higher proportional saving than those with lower baseline levels of use.

It is also possible that the observed patterns of electricity use can be explained by season. As can be seen in Table 2, many of the feedback periods began in the summer months for group 1 and in the winter months for group 2. Detailed information on seasonal use patterns in Northern Ireland could not be obtained from energy providers, but the ONS (Office of National Statistics) publishes information on patterns of use across the UK where temperatures are extremely similar. Domestic use for each quarter of 2009, considered as a proportion of a mean yearly use of 1 was as follows: 1.10 for quarter 1, 0.91 for quarter 2, 0.95 for quarter 3 and 1.04 for quarter 4 (ONS, 2010). Although this measure represents a gross average, it is likely that electricity use would usually be higher during the winter months for most participants, so results may have been confounded by this seasonal variation in use. However, since each feedback or no feedback period lasted for 5 months or longer, most of these periods included some warmer and some colder months, so results may not be entirely explained away by this seasonal variation. It is also extremely unlikely that the results from group 3 represent seasonal variation, as feedback periods were spread across the year.

Some previous work has supported the idea of a relationship between low baseline levels of use and an undesirable response to feedback. For example, Brandon and Lewis (1999) found that consumption during a feedback intervention period was significantly predicted by a combination of environmental beliefs and having been categorized as previously high or low in energy use, with previously high users seeming to respond more favorably to the feedback intervention. Also, Schultz, Nolan, Cialdini, Goldstein and Griskevicius (2007) gave residential users feedback on their personal electricity use and at the same time the average (mean) electricity use for a week for the sample as a whole. They found that participants whose initial use was above average significantly reduced their consumption at follow up, whereas below average users significantly increased their use after this feedback. A second group of households received the same feedback, but what the authors termed 'injunctive norms' were invoked about consumption behavior by placing smiley faces next to feedback information for below average users. They found that in groups where the smiley emoticon was used, below average users kept up their low energy use after normative feedback.

It may be the case that users with initially lower levels of electricity use will react unfavorably to feedback. The influence of 'norms' or perception of average use is an intriguing possibility. It should be an important future goal of scientists to find out who will respond positively to feedback, who will not, and why this difference in response occurs.

Obviously, cultural and social factors such as social use norms can be rebranded as metacontingencies and various presentations of verbal behavior, but as many authors, such as Newsome and Alavosius (2011), Mattaini (2010) and Foxall (2007), point out, the use of behavioral perspectives need not be mutually exclusive of other approaches. The interests of researchers from all fields are best served by the integration of all seemingly successful approaches to explaining and changing damaging behaviors.

The American Council for an Energy Efficient Economy conducted a meta-review of 57 energy conservation feedback studies worldwide, spanning 35 years, which included an interesting analysis of temporal and regional influences (Ehrhardt-Martinez, Donnelly, \& Laitner, 2010). Their results provide examples of the influence of norms or culture on effectiveness of feedback in reducing energy use. In this analysis, feedback studies were grouped according to the era in which they were carried out. Two main energy conservation eras were identified, the 
energy crisis era in the 1970s sparked by the 1973 OPEC embargo, and the more recent climate change era, from 1995 to the present. They found that feedback studies in the climate change era show lower savings than those conducted in the energy crisis era, although feedback studies in Western Europe during the climate change era induced higher savings than those in the USA during this time. This regional effect is attributed by the US-based authors as probably due to differences in culture and political leadership (Ehrhardt-Martinez et al., 2010).

Participants in Group 3 followed a pattern of response that showed a significant drop in electricity use during the second feedback phase, and although some participants did not use more during each no feedback condition than during the feedback condition which preceded it, they all moved towards lower levels of use during the last feedback period than during the first. Their electricity use did not fit a pattern of return to baseline when the feedback was removed. The three participants who completed all five research periods (two no feedback and three feedback periods) had a mean reduction in use of 33\% between the first and the third feedback periods. Although there are many possible explanations for this pattern of results, it does not seem to contradict Darby's (2006b) hypothesis that feedback on conservation performance leads to increases in participant's tacit knowledge ( $p$ 2930) about energy use, therefore producing learning that can be maintained even when the feedback is removed. Given Group 1's results did seem to contradict Darby's hypothesis by demonstrating higher no feedback use after the feedback intervention had concluded, the evidence on whether feedback interventions can produce lasting change after the intervention is removed remains equivocal.

As observed by Newsome and Alavosious, "contrived consequences, such as reward systems for good environmental stewardship, are not always sustainable in practical settings due to costs, time, and other resource constraints" (2011, p. 51). The small-scale investigations described here provide examples of the effect of viable, practical and widely available intervention to reduce electricity use. Interest in the use of feedback as an effective conservation strategy has been growing outside of behavioral psychology, with interest from engineers, environmental scientists and economic disciplines, as well as governments. Interest has been growing particularly in the potential of "smart" meters. Smart meters are utility meters that have enhanced display capabilities, usually involving a display of energy used in monetary terms, and often historical comparisons with the previous day, week, month etc. Many smart meters can also be read remotely for accurate distance billing and may even connect with the internet. As such, smart meters are in the forefront of feedback technology. They can provide complex comparative feedback, and are currently the most likely option for the provision of wide-scale direct feedback on everyday energy use. In the UK, the Department for Energy and Climate Change (DECC), together with the Office of the Gas and Electricity Markets (Ofgem) have now jointly published a plan to roll out smart meters across UK by 2020 (DECC and Ofgem, 2010). Similar plans have been initiated in several areas across the US (Harrison, 2007), accompanied by dissent based on a wide-ranging list of concerns such as cost to consumer, health risks, and privacy issues (Smyth, 2012). Aside from such concerns, and in light of our findings, perhaps we should ask how confident are we that the provision of feedback will lead to reduced energy consumption for all households? It is possible estimates from previous reviews and metaanalyses (Darby, 2006; Ehrhardt-Martinez et al., 2010) of a mean reduction in energy use in the region of $5-15 \%$ as an effect of feedback provision mask important differences in feedback response between below average and above average energy users? We recommend that research in this area must further investigate how households respond to feedback in the field or home setting, over the long term, and also how this may occur differently in different cultural settings. 


\section{FEEDBACK IN THE REAL WORLD}

\section{References}

Abrahmse, W., Steg, L., Vlek, C., Rothengatter, T. (2005). A review of intervention studies aimed at household energy conservation. Journal of Environmental Psychology, 25, 273-291. doi:10.1016/j.jenvp.2005.08.002

Ajzen, I. (1991). The theory of planned behavior. Organizational Behavior and Human Decision Processes, 50, 179-211. doi:10.1016/0749-5978(91)90020-T

Alavosius, M. \& Mattaini, M. A. (2011). Editorial: Behavior Analysis, Sustainability, Resilience and Adaptation. Behavior and Social Issues, 20, 1-5. doi: 10.5210/bsi.v20i0.3782

Bamberg, S. (2003). How does environmental concern influence specific environmentally related behaviors. A new answer to an old question. Journal of Environmental Psychology, 23, 21-32. doi: 10.1016/S02724944(02)00078-6

Becker, L.J. (1978). Joint effect of feedback and goal setting on performance: A field study of residential energy conservation. Journal of Applied Psychology, 63, 428-433. doi:10.1037/0021-9010.63.4.428

Brandon, G. \& Lewis, A. (1999). Reducing household energy consumption: A qualitative and quantitative field study. Journal of Environmental Psychology, 19, 75-85. doi: 10.1006/jevp.1998.0105

Chao, Y. \& Lam, S (2011). Measuring Responsible Environmental Behavior: Self-Reported and Other-Reported Measures and Their Differences in Testing a Behavioral Model. Environment and Behavior, 43, 53-71. doi:10.1177/0013916509350849

Cook, T.D. \& Campbell, D.T. (1979). Quasi-experimentation: Design and analysis issues for field settings. London: Houghton Mifflin.

Darby, S. (2006a). The effectiveness of feedback on energy consumption: a review for DEFRA on the literature on metering, billing and direct displays. Oxford: Environmental Change Institute. Retrieved September 22, 2010 from http://www.eci.ox.ac.uk/research/energy/downloads/smart-metering-report.pdf

Darby, S. (2006b). Social learning and public policy: Lessons from an energy conscious village. Energy Policy, 34, 2929- 2940. doi: 10.1016/j.enpol.2005.04.013

DECC and Ofgem (2010). Smart Metering Implementation Programme Prospectus. Jointly published by The Department for Energy and Climate Change and the Office of the Gas and Electricity Markets (Ofgem) July 2010. Retrieved from: http:/www.decc.gov.uk/assets/decc/Consultations/smart-meter-imp-prospectus/220smart-metering-prospectus-condoc.pdf

Ehrhardt-Martinez, K., Donnelly, K.A., Laitner, J (2010). Advanced Metering Initiatives and Residential Feedback Programs: A Meta-Review for Household Electricity-Saving Opportunities. Retrieved from http://www.aceee.org/sites/default/files/publications/researchreports/e105.pdf

Foxall, G. (2007). Intentional Behaviorism. Behavior and Philosophy, 35, 1-55. Retrieved from http://store.behavior.org/resources/200.pdf

Franzen, A. (2003). Environmental Attitudes in International Comparison: An Analysis of the ISSP Surveys 1993 and 2000. Social Science Quarterly, 84, 297-308. doi: 10.1111/1540-6237.8402005

Frazer, P. (2010). Using Behavioural Analysis to Reduce Domestic Fuel Consumption in Northern Ireland: Feedback and Goal-setting Interventions to Conserve Electricity (Doctoral thesis, University of Ulster, Coleraine, Ireland). Retrieved from http://hdl.handle.net/10788/239

Gardener, G.T. \& Stern, P.C. (2002). Environmental Problems and Human Behavior. Boston: Pearson Custom Publishing.

Guagnano, G.A., Stern, P.C., Dietz, T (1995). Influences on attitude-behavior relationships, a natural experiment with curbside recycling. Environment and Behavior, 27, 699- 718. doi: 10.1177/0013916595275005

Harrison, S. (2007). Smart Metering Projects Map. Retrieved from https://maps.google.com/maps/ms?ie=UTF\&\&hl=en\&msa=0\&msid=115519311058367534348.0000011362ac $6 \mathrm{~d} 7 \mathrm{~d} 21187 \& \mathrm{z}=2$

Hayes, S. C., \& Cone, J. D. (1981). Reduction of residential consumption of electricity through simple monthly feedback. Journal of Applied Behavior Analysis, 14, 81-88. doi: 10.1901/jaba.1981.14-81

Kaiser F.G., Wolfing S., \& Fuhrer U. (1999). Environmental attitude and ecological behavior. Journal of Environmental Psychology, 19, 1-19. doi: 10.1006/jevp.1998.0107

Katzev, R., Cooper, L. \& Fisher, P. (1980-81). The effect of feedback and social reinforcement on residential electricity consumption. Journal of Environmental Systems, 10, 215-227. doi: 10.2190/M8W4-JUYV-NB03CUFL 


\section{FRAZER \& LESLIE}

Lehman, P.K. \& Geller, E.S. (2004). Behavioral analysis and environmental protection: Accomplishments and potential for more. Behavioural and Social Issues, 13, 13-32. doi: 10.5210/bsi.v13i1.33

Mattaini, M. A. (2010). Editorial: Cultural Analysis and Social Change in Medellin. Behavior and Social Issues, 19, 1-5. Retrieved from http://journals.uic.edu/ojs/index.php/bsi. doi: http://dx.doi.org/10.5210/bsi.v19i0.3346

Michigan Stop Smart Meters. (2012). Retrieved July 2012 from http://www.michiganstopsmartmeters.com

Neubert, M.J. (1998). The value of feedback and goal-setting over goal-setting alone and potential moderators of this effect: A meta-analysis. Human Performance, 11, 321-335. doi: 10.1207/s15327043hup1104_2

Newsome, W. D. \& Alavosius, M. P. (2011). Toward the prediction and influence of environmentally relevant behavior: Seeking practical utility in research. Behavior and Social Issues, 20, 44-71. doi: 10.5210/bsi.v20i0.3234

ONS (2010). Energy Trends March 2010. Office of National Statistics \& Department of Energy and Climate Change. Retrieved from https://www.gov.uk/government/uploads/system/uploads/attachment_data/file/65909/4779-energy-trendsmar12.pdf

Pallak, M.S. \& Cummings, N. (1976). Commitment and voluntary energy conservation. Personality and Social Psychology Bulletin, 2, 27-31. doi: 10.1177/014616727600200105

Palmer, M.H., Llyod, M.E. \& Lloyd, K.E. (1977) An experimental analysis of electricity conservation procedures. Journal of Applied Behavior Analysis, 10, 665-671. doi: 10.1901/jaba.1977.10-665

Pelletier, L.G, Lavergne, K.J., \& Sharp, E.C. (2008). Environmental psychology and sustainability: comments on topics important for our future. Canadian Psychology, 49, 257-262. doi: 10.1037/a0013658

Schultz, P.W., Nolan, J.M., Cialdini, R.B., Goldstein, N.J., Griskevicius, V. (2007). The constructive, destructive and reconstructive power of social norms. Psychological Science, 18429- 435. doi: 10.1111/j.14679280.2007.01917.x

Sexton, R. J., Brown Johnson, N., \& Konakayama, A. (1987). Consumer response to continuous-display electricityuse monitors in a time-of use pricing experiment. Journal of Consumer Research, 14, 55-62. Retrieved from http://www.jstor.org/stable/2489242. doi: http://dx.doi.org/10.1086/209092

Staats, H., Harland, P., \& Wilke, H. A. M. (2004). Effecting durable change. A team approach to improve environmental behavior in the household. Environment and Behavior, 36, 341-367. doi: $10.1177 / 0013916503260163$

Smyth, M. (2012, April 1). Smart meter controversy amps up: Province inundated with complaints about soaring B.C. Hydro bills after last week's report. Retrieved from http://www.theprovince.com

Van Houwelligen, J.H., \& Van Raaij, W.F. (1989). The effect of goal-setting and daily electronic feedback on inhome energy use. Journal of Consumer Research 16, 98-105. Retrieved from http://www.jstor.org/stable/2489305. doi: http://dx.doi.org/10.1086/209197

Winett, R. A., Neale, M. S., \& Grier, H. C. (1979). Effects of self-monitoring and feedback on residential electricity consumption. Journal of Applied Behavior Analysis, 12, 173-184. doi: 10.1901/jaba.1979.12-173

Winett, R.A., Hatcher, J.W., Fort, T.R., Leckliter, I.N., Love, S.Q., Riley, A.W., Fishback, J.F. (1982). The effects of videotape modeling and daily feedback on residential electricity conservation, home temperature and humidity, perceived comfort, and clothing worn: winter and summer. Journal of Applied Behavior Analysis, 15, 381-402. doi: 10.1901/jaba.1982.15-381 